entiation, and suppression of polarity, either by the direct effect of various treatments on the protoplasm or by neutralization of internal gradients of nutrients, growth substances, etc., will prevent normal differentiation, but does not necessarily result in the cessation of cell division. On the basis of this hypothesis, the action of glucose on the liverwort sporelings could be due to interference with the normal polar flow of nutrients. Experiments using different nutrients and non-nutrient osmotically active substances may furnish further relevant information. It should perhaps be emphasized that a considerable number of plant materials, such as Conocephalum thalli, many Bryales, and the sporelings of Marsilea undergo normal differentiation on the same glucose medium.

I am indebted to Mr. E. Ashby for the photographs reproduced in Fig. 1.

Department of Cryptogamic Botany, A. Allsopp University of Manchester.

2 Gautheret, R. J., Ann. Rev. Plant Physiol., 6, 433 (1955).

Banning, E., and Wettstein, D. v., Naturwiss., 40, 147 (1953).

Wettstein, D. จ., \%. Bot., 41, 199 (1953).

- Meyer, D. E., Naturwiss., 40, 297 (1954).

- Chalaud, G., Rev. Gén. Bot., 41, 24 (1929).

- Btinning, E., Surv. Biol. Prog., 2, 105 (1952).

"Bünning, E., in "The Growth of Leaves" (London, 1956).

\section{Isolation of Soft Rot Bacteria on Wieringa's Pectate Gel}

THE disintegration or soft rot of the parenchyma of plants is caused by varieties of the coliform bacterium Pectobacterium carotovorum, which secretes enzymes capable of destroying the pectic substances of the cementing layer (middle lamella) of contiguous cells. No other coliform bacteria possess these enzymes.

Bacteria isolated from rotted tissues or from soil on ordinary nutrient agar are mixtures of various types of which those causing rotting can be identified by the further process of testing the action of individual colonies on slices of potato or carrot.

If, however, a 'pectin'-containing medium is used in place of nutrient agar the soft rot bacteria manifest themselves at once by liquefying the medium and thus can be isolated in one operation instead of two.

'The basic element of 'pectin' is galacturonic acid, the COOH groups of which are more or less methoxylated $\left(-\mathrm{OCH}_{3}\right)$. The 'pectins' in common use are highly methoxylated and form a gel only on addition of acid or 95 per cent of sugar, whereas the low methoxylated 'pectins' form a stable gel when calcium ions only are present in sufficient quantity.

Wieringa ${ }^{1}$ devised such a medium by pouring a 'pectin' solution on to well-set calcium agar from which the calcium ions diffused into the 'pectin', which slowly set as a stiff clear gel suitable for streaking plates.

This plating medium has proved highly satisfactory and is much easier to prepare than any other "pectate gel' so far devised. By its use the bacteria responsible for potato black leg can be immediately detected. The medium is made as follows.

(1) The calcium agar. Soil extract, $500 \mathrm{ml}$; sodium chloride, $0.5 \mathrm{gm}$.; calcium chloride, $2.5 \mathrm{gm}$.; yeast extract, $0.5 \mathrm{gm}$.; agar, $10.0 \mathrm{gm}$. Adjust to $p \mathrm{H} 9.0$ and autoclave at $15 \mathrm{lb}$. for $15 \mathrm{~min}$. Pour enough to cover the bottom of Petri dishes and place in a desiccator to dry thoroughly (about 2 days).

(2) The 'pectin' solution. Prepare a 2 per cent sodium polypectate solution by adding the powder slowly to hot distilled water, stirring all the time. Add 4 per cent bromo-thymol blue and adjust the $p \mathrm{H}$ to 8.0 by adding $N$ sodium hydroxide drop by drop. Autoclave at $10 \mathrm{lb}$. for $2 \mathrm{~min}$. When cold pour just enough to cover the surface of the agar plates and leave to set and dry in a desiccator (about 8 days). The plates are ready for streaking if no liquid exudes from between the layers of pectate gel and agar when the plates are slightly tipped up. They keep well under a bell-jar at laboratory temperature.

\section{Botany School,}

Cambridge.

$$
\text { Jan. } 12 .
$$

${ }^{1}$ Wieringa, K. T., Rep. Proc. Fourth Internat. Cong. Microbiology, Copenhagen, 1947, p. 482 (1949).

\section{Surface Microflora of Pine Needles}

IN East Anglia, the crowns of pines (Pinus sylvestris and $P$. nigra var. calabrica) bear large numbers of fungal spores. Their presence is readily shown by allowing water to percolate through freshly collected needles on to sections of pine stem about $1 \mathrm{~cm}$. thick and $7 \mathrm{~cm}$. in diameter and then incubating these in Petri dishes at $22^{\circ} \mathrm{C}$.

With unsterilized sections, the substrate favours growth of wood-rotting basidiomycetes and, to a lesser extent, blue-stain fungi; with autoclaved sections a variety of other fungi predominate, basidiomycetes being largely suppressed by competition. The surface spore population of pine needles is readily washed off and may be estimated by plating suitable dilutions of washings on to sections of stem and also with malt agar; the number of colonies developing may be counted after about ten days. Thus in early December 1956, the approximate counts per needle for a sample of foliage from a pine plantation were as follows: Fomes annosus, 1 ; Cladosporium sp., 4; Peniophora gigantea, 6; Sclerophoma pithyophila, 14 ; and Ophionectria cylindrospora, 60 .

Under some conditions, therefore, the total spore population of such species on a single crown is measurable in hundreds of thousands, if not in millions. The proportion of various species varies with locality and, with basidionacetes, this probably reflects the extent of spore discharge in the vicinity. $F$. annosus has been detected on pine foliage in many localities in Thetford Chase; but, as might be expected, it cannot readily be detected on the foliage of pines in shelter-belts remote from this forest. In a given locality, the spore population fluctuates with time, probably through loss in viability and washing off by rain. $F$. annosus, $P$. gigantea and Stereum sanguinolentum, together with blue-stain and other woodinhabiting fungi, have been detected in water drops falling from the tree canopy just after rain.

This two-stage dispersal of basidiospores, by wind and water droplet, is almost certainly important in determining the chances of stump infection by the parasite $F$. annosus and other fungi, and may well be significant also for initiating mycorrhizal infection of rootlets. The apparent efficiency of pine needles in trapping wind-borne spores is doubtless related 